\title{
Efektivitas Penerapan Automated Dose Dispensing di Bangsal Rawat Inap Rumah Sakit Umum Kabupaten Tangerang
}

\author{
Abiyoga Pradata ${ }^{1}$, Retnosari Andrajati ${ }^{2}$, Mahdi Jufri ${ }^{3}$, Ayup Milladi ${ }^{4}$ \\ ${ }^{1}$ Program Studi Magister Farmasi, Peminatan Farmasi Klinik, Universitas Indonesia, \\ Depok, Indonesia, ${ }^{2}$ Departemen Farmasi Klinik, Universitas Indonesia, Depok, \\ Indonesia, ${ }^{3}$ Departemen Teknologi Farmasi, Universitas Indonesia, Depok, Indonesia, \\ ${ }^{4}$ Instalasi Farmasi Rumah Sakit Umum Kabupaten Tangerang, Tangerang, Indonesia
}

\begin{abstract}
Abstrak
Penerapan dan penelitian terkait efektivitas automated dose dispensing (ADD) di Indonesia masih sangat terbatas. Oleh karena itu, penelitian ini bertujuan untuk melihat efektivitas ADD di salah satu rumah sakit di Indonesia yang telah menerapkannya, yaitu Rumah Sakit Umum Kabupaten Tangerang. Metode penelitian yang digunakan adalah cross-sectional study dengan membandingkan jumlah dispensing error dan dispensing time dari populasi resep yang menggunakan ADD dan manual dispensing (MD). Sampel didapat dari resep unit dose dispensing (UDD) bangsal rawat inap RSU Kabupaten Tangerang periode Mei-Juli 2019. Hasil penelitian dari 1086 resep untuk masing-masing populasi menunjukkan terdapat perbedaan rata-rata geometrik dispensing time yang signifikan $(\mathrm{p}<0,001)$ antara ADD yaitu $53,70(52,48-54,95)$ detik dengan MD yaitu 144,54 (141,25-147,91) detik. Hasil penelitian ini juga memaparkan terdapat perbedaan jumlah resep dengan dispensing error yang signifikan $(p<0,002)$ antara ADD yaitu 44 errors dan MD yaitu 77 errors dengan nilai odds ratio sebesar 1,83. Hal ini menunjukkan bahwa di RSU Kabupaten Tangerang, ADD lebih efektif dibandingkan dengan MD dilihat dari ratarata geometrik dispensing time dan jumlah resep dengan dispensing error. Meskipun ADD dapat mempercepat dispensing time dan menurunkan jumlah dispensing error, penting dilakukan telaah sebelum menerapkan mesin ini dengan mempertimbangkan faktor biaya, sistem informasi rumah sakit, resep elektronik, dan keterampilan sumber daya manusia.
\end{abstract}

Kata kunci: Automated dose dispensing, dispensing time, dispensing error, dose dispensing

\section{Effectiveness of Automated Dose Dispensing Implementation in Inpatient Ward of Tangerang District General Hospital}

\begin{abstract}
The application and research related to the effectiveness of automated dose dispensing (ADD) in Indonesia is still very limited. Therefore, this study aimed to investigate the effectiveness of ADD in a hospital in Indonesia that have implemented this method, that is Tangerang District General Hospital. This research was cross sectional study by comparing the number of recipes with dispensing error and dispensing time of the recipe population using ADD and manual dispensing (MD). Samples were obtained from the prescription unit dose dispensing (UDD) inpatient ward of Tangerang District Hospital in the period of May-July 2019. The result of 1086 prescriptions for each population showed a significant difference $(\mathrm{p}<0.001)$ in the geometric mean of dispensing time between ADD $53.70(52.48-54.95)$ seconds and MD 144.54 (141.25-147.91) seconds. There were differences in the number of recipes with a significant dispensing error $(\mathrm{p}<0.002)$ between ADD 44 errors and MD 77 errors with an odds ratio of 1.83 . This shows that in Tangerang District General Hospital, ADD was more effective compared to MD in terms of the geometric mean of dispensing time and the number of prescriptions with dispensing error. Although ADD can speed up dispensing time and reduce the number of dispensing errors, it is important to conduct a study before implementing this machine by considering cost factors, hospital information systems, electronic prescriptions, and human resource skills.
\end{abstract}

Keywords: Automated dose dispensing, dispensing time, dispensing error, unit dose dispensing

Korespondensi: Abiyoga Pradata, S.Farm., Apt., Program Studi Magister Farmasi, Peminatan Farmasi Klinik, Universitas Indonesia, Depok, Jawa Barat 16424, Indonesia, email: abiyoga.pradata@gmail.com

Naskah diterima: 14 Agustus 2019, Diterima untuk diterbitkan: 21 November 2019, Diterbitkan: 28 Desember 2019 


\section{Pendahuluan}

Medication errors masih menjadi salah satu masalah utama dalam pelayanan kesehatan di berbagai negara. Medication errors sendiri merupakan kejadian yang dapat mengarah pada penggunaan obat yang tidak sesuai yang seharusnya dapat dicegah. ${ }^{1}$ Hasil penelitian di Inggris menyatakan bahwa terdapat 237 juta kasus medication erros yang berkontribusi pada 1.708 kematian, peningkatan lama rawat inap, dan menghabiskan biaya sebesar 98,5 juta euro setiap tahunnya. ${ }^{2}$ Besaran jumlah tersebut diperkirakan serupa dengan negara lain yang memiliki mutu pelayanan kesehatan yang setara, contohnya Amerika Serikat dan negara-negara Eropa. ${ }^{2}$ Di Indonesia sendiri, ditemukan sebanyak 1.563 medication errors dari 7.762 dosis obat yang dikaji di salah satu rumah sakit di Bali. ${ }^{3}$

Salah satu jenis medication errors yang sering terjadi adalah dispensing errors. ${ }^{4,5}$ Presentasi kejadian dispensing error di setiap negara bervariasi, yaitu antara $0,015 \%$ sampai $33,5 \%{ }^{6}$ Sebuah penelitian melaporkan adanya kejadian dispensing error sebanyak 4,58 per 1000 item obat terdispensi. ${ }^{7}$ Pencatatan dan investigasi kejadian dispensing error sangat penting dilakukan untuk mengidentifikasi faktor-faktor yang berpengaruh dan sebagai upaya mengembangkan strategi pencegahan. ${ }^{6}$

Berdasarkan Permenkes No. 72 tahun 2016 tentang Standar Pelayanan Kefarmasian di Rumah Sakit, salah satu cara untuk dapat menurunkan medication error hingga di bawah 5\% adalah dengan metode distribusi unit dose dispensing (UDD), namun metode ini sulit diterapkan karena meningkatkan beban kerja pegawai dan membutuhkan waktu pengerjaan yang lebih lama. Salah satu solusi untuk mengatasinya adalah dengan menggunakan mesin automated dose dispensing (ADD) yang dapat membantu proses dispensing obat secara otomatis. ${ }^{8}$ Penggunaan ADD diketahui dapat menurunkan angka dispensing error hingga $35 \%$, yaitu dari $50,33 \pm 34,77$ menjadi $15,67 \pm 6,282 .{ }^{9}$ Pada penelitian lain bahkan disebutkan bahwa dispensing dengan metode ADD dilakukan hampir tanpa kesalahan dan dapat menurunkan waktu dispensing hingga $50 \% .^{10,11}$

ADD masih tergolong baru di Indonesia. Penelitiannya juga masih sangat terbatas dan kurang konklusif, sehingga efektivitas mesin ADD di Indonesia masih dipertanyakan. ${ }^{9}$ Salah satu rumah sakit di Indonesia yang telah menerapkan ADD adalah Rumah Sakit Umum (RSU) Kabupaten Tangerang. Meskipun telah berjalan sejak tahun 2017, penelitian terkait ADD di rumah sakit ini masih sangat terbatas. Oleh karena itu, penelitian ini dilakukan untuk memberikan gambaran efektivitas penerapan ADD di salah satu rumah sakit di Indonesia dengan cara membandingkan dispensing error dan dispensing time antara pengerjaan resep rawat inap secara ADD dan secara manual dispensing (MD).

\section{Metode}

Desain penelitian dan persetujuan etik Desain penelitian ini adalah kuantitatif dengan menggunakan pendekatan cross-sectional study dari dua populasi, yaitu populasi resep UDD yang dikerjakan menggunakan ADD dan MD di bangsal rawat inap RSU Kabupaten Tangerang. ADD yang digunakan adalah tipe automatic tablet dispensing \& packaging system machine (ATDPS) seri 400SL ACRS2 yang di produksi oleh JVM, Korea Selatan. Penelitian ini telah mendapatkan persetujuan laik etik yang dikeluarkan oleh Komite Etik Penelitian Kesehatan Fakultas Kedokteran Universitas Indonesia dengan nomor KET999/UN2.F1/ETIK/PPM.00.02/2019.

\section{Objek penelitian}

Objek penelitian ini adalah seluruh resep UDD di bangsal rawat inap RSU Kabupaten Tangerang, Banten pada Mei 2019 hingga Juli 
2019. UDD pada rumah sakit ini diterapkan di bangsal perawatan bedah, infeksius paru, syaraf, kulit, jantung dan penyakit dalam. Kriteria inklusi adalah resep oral UDD yang dikerjakan menggunakan ADD atau dengan MD. Kriteria eksklusi adalah resep racikan, resep tanpa obat oral serta resep dengan jumlah obat lebih dari sembilan. Variabel bebas pada penelitian ini adalah ADD dengan variabel terikat yaitu dispensing error dan dispensing time, sedangkan variabel perancunya antara lain jumlah item obat yang tertera pada resep, lama pengalaman apoteker dan tenaga teknis kefarmasian (TTK). Luaran pada penelitian ini adalah efektivitas penerapan ADD dilihat dari dispensing time dan kejadian dispensing error di Instalasi Farmasi Rawat Inap RSU Kabupaten Tangerang.

Prosedur pengambilan data

Pengambilan data dilakukan oleh dua orang yang berkompetensi sebagai apoteker dengan cara mencatat dispensing time menggunakan stopwatch dan mencatat setiap resep dengan kejadian dispensing errors. Pencatatan pada MD dimulai dari penyiapan kemasan UDD hingga pengambilan obat selesai, sedangkan pada ADD dimulai dari pengolahan data resep dalam aplikasi ADD (OnCube) hingga obat keluar dari mesin.

Analisis statistik

Analisis pada dispensing time dilakukan dengan menggunakan analisis bivariat uji $\mathrm{t}$ tidak berpasangan dan analisis multivariat uji Ancova, sedangkan analisis pada dispensing error dilakukan dengan analisis bivariat uji Chi-Square dan analisis multivariat uji regresi logistik. Analisis multivariat bertujuan untuk melihat hubungan murni antara variabel bebas dan variabel terikat setelah mengontrol variabel perancu berupa jumlah item obat dan pengalaman apoteker dan TTK. Analisis statistik dilakukan menggunakan IBM SPSS Statistics Base Versi 22.

\section{Hasil}

Hasil pengumpulan data

Dari total 2416 resep UDD, diperoleh 2172 sampel resep yang memenuhi kriteria inklusi, dengan 1086 sampel untuk populasi resep menggunakan ADD dan 1086 sampel untuk resep menggunakan MD (Gambar 1).

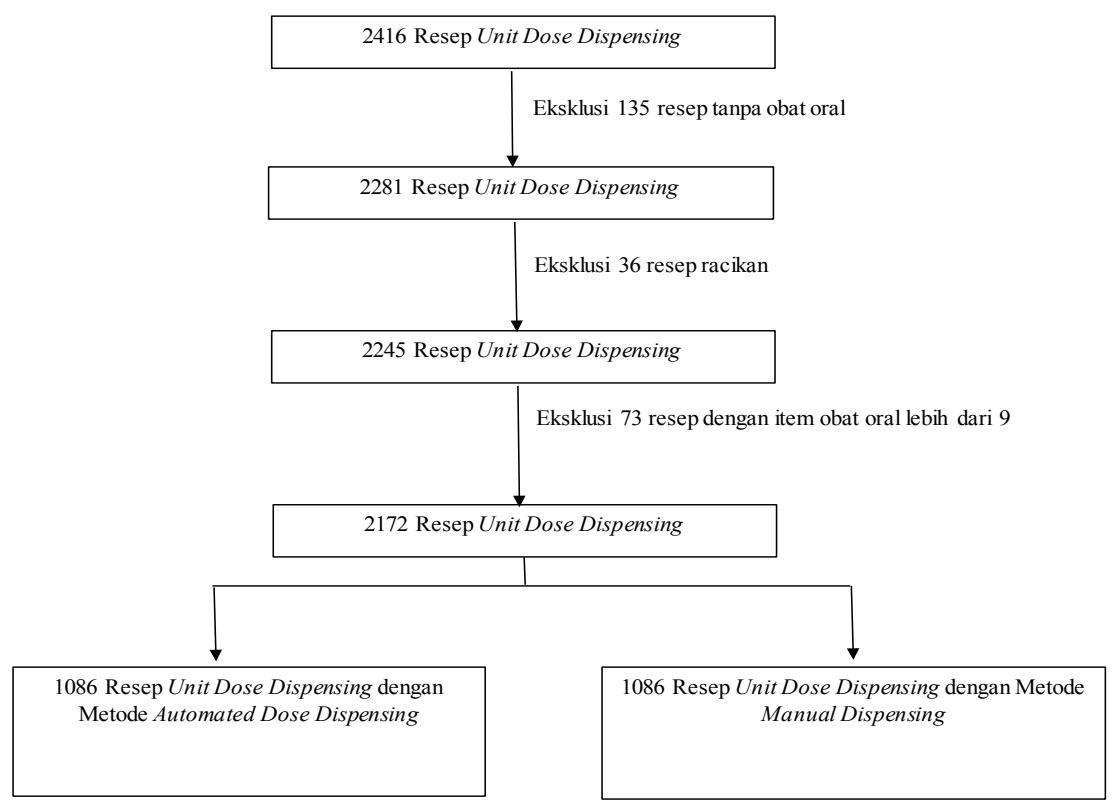

Gambar 1 Alur Perolehan Data Resep di Bangsal Rawat Inap RSU Kabupaten Tangerang 
Tabel 1 Hasil Analisis Bivariat dan Multivariat antara Automated Dose Dispensing dan Manual Dispensing Terhadap Dispensing Time

\begin{tabular}{|c|c|c|c|c|c|}
\hline \multicolumn{2}{|c|}{ Model } & \multirow{2}{*}{$\begin{array}{c}\mathbf{n} \\
1086\end{array}$} & \multirow{2}{*}{$\begin{array}{c}\begin{array}{c}\text { Rata-rata Geometrik } \\
\text { Dispensing Time (IK95\%) }\end{array} \\
53,70(51,28-56,23)\end{array}$} & \multirow{2}{*}{$\begin{array}{c}\begin{array}{c}\text { Perbandingan } \\
\text { Rata-rata }(\mathbf{I K 9 5 \% )}\end{array} \\
0,37(0,35-0,38)\end{array}$} & \multirow{2}{*}{$\begin{array}{l}\text { Nilai } \mathbf{p} \\
<0,001\end{array}$} \\
\hline Unadjusted $^{\mathrm{a}}$ & ADD & & & & \\
\hline & MD & 1086 & $144,54(141,25-151,35)$ & & \\
\hline \multirow[t]{2}{*}{ Adjusted $^{\mathrm{b}}$} & ADD & 1086 & $53,70(52,48-54,95)$ & $0,37(0,36-0,38)$ & $<0,001$ \\
\hline & MD & 1086 & $144,54(141,25-147,91)$ & & \\
\hline
\end{tabular}

Keterangan $={ }^{\text {a } U j i ~ t ~ t i d a k ~ b e r p a s a n g a n ; ~}{ }^{\text {} U j i ~ r e g r e s i ~ l i n e a r, ~ d e n g a n ~ v a r i a b e l ~ p e r a n c u ~ y a n g ~ d i k o n t r o l ~ a d a l a h ~ j u m l a h ~ i t e m ~ o b a t, ~}$ pengalaman apoteker, dan pengalaman tenaga teknis kefarmasian (TTK); $\mathrm{ADD}=$ Automated dose dispensing; $\mathrm{MD}=$ Manual dispensing

Hasil analisis dispensing time

Hasil dari analisis bivariat dan multivariat dispensing time tidak jauh berbeda, seperti yang dapat dilihat pada Tabel 1. Analisis multivariat sebagai analisis akhir, bertujuan untuk melihat hubungan murni antara variabel bebas dan variabel terikat setelah mengontrol variabel perancu. Hasil analisis multivariat menujukkan terdapat perbedaan rata-rata geometrik dispensing time yang signifikan $(\mathrm{p}<0,001)$ antara pengerjaan resep secara ADD yaitu 53,70 (52,48-54,95) detik dengan pengerjaan resep secara MD yaitu 144,54 (141,25-147,91) detik. Rata-rata yang digunakan adalah rata-rata geometrik, karena sebaran data dispensing time yang tidak normal menyebabkan perlu dilakukan transformasi menggunakan log. Data pada Tabel 1 adalah hasil transformasi balik dari log dispensing time.

Hasil analisis dispensing error Hasil dari analisis bivariat dan multivariat dispensing error dapat dilihat pada Tabel 2.
Hasil analisis multivariat menunjukkan bahwa terdapat perbedaan jumlah resep dengan dispensing error yang signifikan $(\mathrm{p}<0,002)$ antara ADD yaitu 44 errors dan MD yaitu 77 errors dengan nilai odds ratio sebesar 1,83.

\section{Pembahasan}

Metode distribusi UDD dengan menggunakan ADD di RSU Kabupaten Tangerang telah diterapkan sejak 2017 pada beberapa bangsal rawat inap, namun belum terintegrasi dengan resep elektronik. Tipe ADD di rumah sakit ini adalah ATDPS, yang hanya dapat melakukan dispensing pada obat dalam bentuk sediaan tablet, kaplet, dan kapsul. ATDPS dengan seri 400SL ACRS2 yang digunakan di rumah sakit ini terdiri dari 400 cannister, dengan kecepatan dispensing hingga 60 kemasan UDD per menit. Cannister sebagai tempat menyimpan obat pada ADD rata-rata dapat menampung 50 hingga 200 tablet/kapsul tergantung ukurannya. Sebelum obat dapat dimasukkan ke dalam cannister, obat harus

Tabel 2 Hasil Analisis Bivariat dan Multivariat antara Automated Dose Dispensing dan Manual Dispensing Terhadap Resep dengan Dispensing Error

\begin{tabular}{lcccccc}
\hline & \multicolumn{2}{c}{ Dispensing Error } & \multicolumn{2}{c}{ Unadjusted $^{\mathbf{a}}$} & \multicolumn{2}{c}{ Adjusted $^{\mathbf{b}}$} \\
\cline { 2 - 7 } & $\begin{array}{c}\text { Tidak Ada } \\
(\mathbf{n}=\mathbf{2 0 5 1})\end{array}$ & $\begin{array}{c}\text { Ada } \\
(\mathbf{n}=\mathbf{1 2 1})\end{array}$ & Nilai p & $\begin{array}{c}\text { OR } \\
(\mathbf{I K 9 5 \% )}\end{array}$ & Nilai p & $\begin{array}{c}\text { OR } \\
(\text { IK95\%) }\end{array}$ \\
\hline ADD & $1042(95,90 \%)$ & $44(4,10 \%)$ & 0,003 & $1,80(1,23-2,64)$ & 0,002 & $1,83(1,25-2,69)$ \\
MD & $1009(92,90 \%)$ & $77(7,10 \%)$ & & & & \\
\hline
\end{tabular}

Keterangan: $\mathrm{ADD}=$ Automated dose dispensing; $\mathrm{MD}=$ Manual dispensing; ${ }^{\mathrm{a} U j \mathrm{ji}}$ Chi-Square; ${ }^{\mathrm{b}} \mathrm{Uji}$ regresi logistik, dengan variabel perancu yang dikontrol adalah jumlah item obat, pengalaman apoteker, dan pengalaman tenaga teknis kefarmasian (TTK) 
melewati proses deblistering, yaitu proses pemisahan obat dengan kemasan primernya seperti alumunium foil atau blister. ADD juga memiliki special tablet system (STS) yang memungkinkan dispensing obat-obat khusus seperti setengah tablet, obat yang tidak ada pada cannister, dan sebagainya.

Berdasarkan hasil penelitian, dispensing time resep UDD yang menggunakan ADD lebih cepat secara signifikan $(p<0,001)$ jika dibandingkan dengan MD. Resep dengan $\mathrm{ADD}$, setelah mengontrol variabel perancu, memiliki rata-rata geometrik 53,70 (52,4854,95) detik, sedangkan MD 144,54 (141,25147,91) detik. Hal ini dapat disebabkan proses etiket dan pengambilan obat dengan ADD dikerjakan oleh mesin secara otomatis dalam waktu hampir bersamaan sehingga mempersingkat pengerjaan resep, sedangkan pada MD pengerjaan etiket dilakukan dengan cara ditulis manual. Proses pengambilan obat secara manual oleh TTK juga lebih lama dibandingkan ADD karena pencarian obat yang dibutuhkan dilakukan secara satu per satu. Hasil ini sesuai dengan penelitian lain yang menyatakan ADD dapat meningkatkan kecepatan pelayanan dan mengurangi waktu kerja pegawai hingga 2 jam. ${ }^{12-13}$

Berdasarkan hasil pengamatan, meskipun ADD dapat mengurangi waktu kerja pegawai, ADD justru meningkatkan tanggung jawab bagi apoteker. Hal ini dapat disebabkan penggunaan dan pemeliharaan mesin ADD lebih banyak dilakukan oleh apoteker. Suatu penelitian memaparkan bahwa penggunaan ADD menurunkan beban kerja TTK namun meningkatkan beban kerja apoteker. ${ }^{14}$ Meski demikian, peningkatan beban kerja apoteker ini memiliki hubungan pula dengan adanya peningkatan pelayanan kepada pasien yang lebih komperehensif oleh apoteker. ${ }^{14}$

Salah satu faktor yang dapat memperlambat kinerja ADD di rumah sakit tempat penelitian adalah belum diterapkannya resep elektronik, sehingga diperlukan pengolahan data resep yang lebih lama sebelum dilakukan dispensing oleh mesin. Faktor lainnya adalah penggunaan STS pada ADD. Semakin sering penggunaan STS, akan semakin lama dispensing time oleh ADD karena TTK harus mencari obat secara manual sebelum dimasukkan ke dalam STS satu per satu. Proses deblistering juga menjadi salah satu faktor yang memperlambat ADD. Di Indonesia, umumnya obat memiliki kemasan primer berupa strip alumunium foil atau blister yang memakan waktu dalam proses deblistering. Permasalahan ini sebenarnya dapat diselesaikan apabila industri farmasi Indonesia menyediakan kemasan loose pack seperti di negara lain.

Penelitian ini juga menunjukkan bahwa resep menggunakan ADD memiliki jumlah resep dengan dispensing error yang lebih sedikit yaitu 44 errors, berbeda signifikan $(\mathrm{p}<0,05)$ dibandingkan menggunakan MD yaitu 77 errors. Hasil ini sesuai dengan hasil dari beberapa penelitian yang menyatakan terdapat penurunan dispensing error setelah penerapan mesin dispensing otomatis. ${ }^{9-11}$ Hal ini dapat disebabkan ADD mengurangi proses pengerjaan yang dilakukan manusia. Semakin banyak keterlibatan manusia, potensi kesalahan akan semakin besar. ${ }^{11}$

Dispensing error yang dicatat pada penelitian ini antara lain kesalahan petunjuk label, bentuk sediaan, kekuatan obat, jenis obat, jumlah obat, nama pasien, dan obat yang rusak. Berdasarkan hasil pengamatan, dispensing error yang paling sering terjadi pada proses ADD adalah kesalahan jumlah obat yang terdispensi. Hal ini disebabkan bentuk dan ukuran obat yang berubah dari perusahaan farmasi dan tidak sesuai dengan ukuran cannister obat tersebut. Setiap cannister dibuat khusus untuk satu ukuran obat saja, sehingga ketika ukuran obat tersebut berbeda maka obat tidak dapat keluar dari cannister secara sempurna, contohnya tablet captopril atau ramipril yang terdispensi ganda karena perubahan ukuran tablet dari industri farmasi. 
Berbeda dengan ADD, dispensing error yang sering terjadi pada MD adalah kesalahan penulisan petunjuk etiket, baik berupa tanggal maupun aturan pakai. Hal ini umumnya dapat terjadi ketika resep yang dikerjakan berjumlah banyak sehingga terjadi peningkatan beban kerja pegawai farmasi yang berujung pada peningkatan potensi kesalahan. ${ }^{11}$

Kelebihan lain yang dimiliki ADD adalah informasi etiket yang tidak dimiliki MD, antara lain nama obat lengkap, jumlah tablet/ kapsul, nama dokter penanggung jawab, jam minum obat secara spesifik, dan nomor rekam medik pasien. Kelengkapan informasi pada etiket berpengaruh pada kemungkinan terjadi medication error. ${ }^{3}$ Kelemahan ADD yang lain antara lain diperlukan kestabilan bentuk obat dalam cannister, deblistering obat yang memakan waktu, diperlukan pegawai yang terlatih, serta biaya tinggi di awal pembelian. ${ }^{8}$ Sistem resep elektronik, sistem informasi rumah sakit yang terintegrasi dengan ADD, dan komitmen pimpinan sejak perencanaan, persiapan, hingga implementasinya sangat mendukung luaran dari penerapan ADD. ${ }^{8,15}$

Keterbatasan pada penelitian ini adalah waktu deblistering tidak dimasukkan ke dalam waktu dispensing time karena hanya dilakukan satu hingga dua kali dalam seminggu. Selain itu, penelitian ini juga tidak meneliti efektivitas ADD yang optimalnya terintegrasi dengan resep elektronik.

\section{Simpulan}

Resep UDD yang menggunakan ADD lebih efektif dibandingkan MD dilihat dari rata-rata geometrik dispensing time dan jumlah resep dengan dispensing error di bangsal rawat inap RSU Kabupaten Tangerang. Meskipun ADD dapat mempercepat pelayanan resep dan menurunkan jumlah dispensing error, penting dilakukan telaah sebelum menerapkan mesin ini dengan mempertimbangkan faktor biaya, sistem informasi rumah sakit, resep elektronik, dan keterampilan sumber daya manusia.

\section{Pendanaan}

Penelitian ini tidak didanai oleh sumber hibah manapun.

\section{Konflik Kepentingan}

Seluruh penulis menyatakan tidak terdapat potensi konflik kepentingan dengan penelitian, kepenulisan (authorship), dan atau publikasi artikel ini.

\section{Daftar Pustaka}

1. Lisby M, Nielsen LP, Brock B, Mainz J. How are medication errors defined? A systematic literature review of definitions and characteristics. Int J Qual Health Care. 2010;22(6):507-18. doi: 10.1093/intqhe/ mzq059.

2. Elliott RA, Camacho E, Campbell F, Jankovic D, Martyn-St James M, Kaltenthaler E, et al. Prevalence and economic burden of medication errors in the NHS in England: Rapid evidence synthesis and economic analysis of the prevalence and burden of medication error in the UK. York, England: Policy Research Unit in Economic Evaluation of Health and Care Interventions (EEPRU); 2018.

3. Ernawati DK, Lee YP, Hughes JD. Nature and frequency of medication errors in a geriatric ward: An Indonesian experience. Ther Clin Risk Manag. 2014;10:413-21. doi: 10.2147/TCRM.S61687.

4. Chen Y, Wu X, Huang Z, Lin W, Li Y, Yang J, et al. Evaluation of a medication error monitoring system to reduce the incidence of medication errors in a clinical setting. Res Social Adm Pharm. 2019;15(7):883-8. doi: 10.1016/j.saphar 
m.2019.02.006.

5. Kenawy AS, Kett V. The impact of electronic prescription on reducing medication errors in an Egyptian outpatient clinic. Int J Med Inform. 2019;127:80-7. doi: 10.1016/j.ijmedinf.2019.04.005

6. Aldhwaihi K, Schifano F, Pezzolesi C, Umaru N. A systematic review of the nature of dispensing errors in hospital pharmacies. Integr Pharm Res Pract. 2016;5:1-10. doi: 10.2147/IPRP.S95733

7. Sanchez AMM. Incidence, type and causes of dispensing errors: A study from the community pharmacy. Afr J Pharm Pharmacol. 2013;7(13):715-20. doi: 10.5 897/AJPP2013.2991

8. Karundeng DJ, Permanasari VY. Automated dispensing machine sebagai salah satu upaya menurunkan mediaction errors di farmasi rumah sakit. Cermin Dunia Kedokt. 2018;45(10):741-6.

9. Sujatno P, Pinzon RT, Meliala A. Evaluasi dampak penerapan automated dispensing machine terhadap dispensing error di farmasi rawat jalan instalasi farmasi rumah sakit bethesda Yogykarta. J Pharm Sci Comnty. 2016;13(1):7-14. doi: 10.24 071/jpsc.131124

10. Beard RJ, Smith P. Integrated electronic prescribing and robotic dispensing: A case study. Springerplus. 2013;2:295. doi: 10.1186/2193-1801-2-295
11. Ong YSP, Chen LL, Wong JA, Gunawan Y, Goh WJ, Tan MC, et al. Evaluating the impact of drug dispensing systems on the safety and efficacy in a singapore outpatient pharmacy. Value Health. 2014; 17(7):A791-2. doi: 10.1016/j.jval.2014.0 8.440 .

12. Suryadinata HU. The benefits of automated dispensing machine for hospital pharmacy in Indonesia: Situation, implementation, and feasibility. Glob Health Manag J. 2017;1(1):15-22.

13. Tsao NW, Lo C, Babich M, Shah K, Bansback NJ. Decentralized automated dispensing devices: Systematic review of clinical and economic impacts in hospitals. Can J Hosp Pharm. 2014;67(2):138-48. doi: 10.4212/cjhp.v67i2.1343

14. Noparatayaporn P, Sakulbumrungsil R, Thaweethamcharoen T, Sangseenil W. Comparison on human resource requirement between manual and automated dispensing systems. Value Health Reg Issues. 2017; 12:107-11. doi: 10.1016/j.vhri.2017.03.0 07.

15. European Directorate for the Quality of Medicines \& HealthCare. Automated dose dispensing (ADD) guidelines on best practice for the ADD process, and care and safety of patients. Strasbourg, France: Council of Europe EDQM; 2018. 